\title{
Examining the effect of pore size distribution and shape on flow through unsaturated peat using computed tomography
}

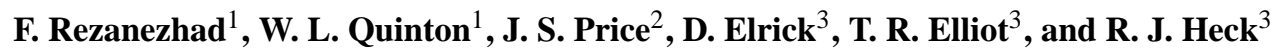 \\ ${ }^{1}$ Cold Regions Research Centre, Wilfrid Laurier University, Waterloo, Canada \\ ${ }^{2}$ Department of Geography, University of Waterloo, Waterloo, Canada \\ ${ }^{3}$ Department of Land Resource Science, University of Guelph, Guelph, Canada
}

Received: 30 April 2009 - Published in Hydrol. Earth Syst. Sci. Discuss.: 15 May 2009

Revised: 5 October 2009 - Accepted: 13 October 2009 - Published: 28 October 2009

\begin{abstract}
The hydraulic conductivity of unsaturated peat soil is controlled by the air-filled porosity, pore size and geometric distribution as well as other physical properties of peat materials. This study investigates how the size and shape of pores affects the flow of water through peat soils. In this study we used X-ray Computed Tomography (CT), at $45 \mu \mathrm{m}$ resolution under 5 specific soil-water pressure head levels to provide 3-D, high-resolution images that were used to detect the inner pore structure of peat samples under a changing water regime. Pore structure and configuration were found to be irregular, which affected the rate of water transmission through peat soils. The 3-D analysis suggested that pore distribution is dominated by a single large pore-space. At low pressure head, this single large air-filled pore imparted a more effective flowpath compared to smaller pores. Smaller pores were disconnected and the flowpath was more tortuous than in the single large air-filled pore, and their contribution to flow was negligible when the single large pore was active. We quantify the pore structure of peat soil that affects the hydraulic conductivity in the unsaturated condition, and demonstrate the validity of our estimation of peat unsaturated hydraulic conductivity by making a comparison with a standard permeameter-based method. Estimates of unsaturated hydraulic conductivities were made for the purpose of testing the sensitivity of pore shape and geometry parameters on the hydraulic properties of peats and how to evaluate the structure of the peat and its affects on parameterization. We also studied the ability to quantify these factors for different soil moisture contents in order to define how the factors controlling the shape coefficient vary with changes in soil
\end{abstract}

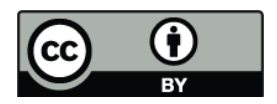

Correspondence to: F. Rezanezhad (frezanezhad@wlu.ca) water pressure head. The relation between measured and estimated unsaturated hydraulic conductivity at various heads shows that rapid initial drainage, that changes the air-filled pore properties, creates a sharp decline in hydraulic conductivity. This is because the large pores readily lose water, the peat rapidly becomes less conductive and the flow path among pores, more tortuous.

\section{Introduction}

Understanding the nature of water flow and storage in peat deposits requires a knowledge of the unique physical properties of this porous medium. For instance, the increasing degree of decomposition with depth below the ground surface results in a decrease in the size of particles and interparticle pores, and an increase in the bulk density (Verry and Boelter, 1978; Quinton et al., 2000). The total porosity includes the volume fraction of the relatively large, interparticle pores that actively transmit water, referred to as the "active porosity", and the relatively small, closed, and deadend pores formed by the remains of plant cells, i.e. the "inactive porosity" (Hoag and Price, 1997). The reduction in the total porosity with depth is small compared with the reduction in active porosity, while the active porosity typically decreases from $\sim 0.8$ near the ground surface to $<0.5$ in wellhumified peat (Quinton et al., 2000). With the reduction in active porosity and decrease in pore size, the saturated hydraulic conductivity of peat typically decreases by several orders of magnitude between the ground surface and a depth of $\sim 0.5 \mathrm{~m}$ (Hoag and Price, 1995; Quinton et al., 2008). Although, some studies report that layering of peat and other factors give a more complicated relation between hydraulic conductivity and depth (e.g. Beckwith et al., 2003).

Published by Copernicus Publications on behalf of the European Geosciences Union. 
Equations relating permeability to other measurable properties of porous materials are used in the various fields of research concerned with the flow of water, oil or gases through soils, porous rocks etc., and can be applied to peat. Hubbert (1956) showed that Darcy's law can be derived as a special case of the Navier-Stokes equation by considering the relationships between driving and resisting forces at the microscopic scale, and expressed the relationship between hydraulic conductivity $\left(K\left[\mathrm{~L} \mathrm{~T}^{-1}\right]\right)$ and permeability by:

$K=K^{*} \frac{\rho g}{\mu}$

where $K^{*}\left[\mathrm{~L}^{2}\right]$ is the intrinsic permeability of a porous medium, $\rho\left[\mathrm{ML}^{-3}\right]$ is the fluid density, $g\left(=9.8 \mathrm{~L} \mathrm{~T}^{-2}\right)$ is gravitational acceleration, and $\mu\left[\mathrm{ML}^{-1} \mathrm{~T}^{-1}\right]$ is the dynamic viscosity of the fluid. Since $\rho$ and $\mu$ are known for a given temperature, the challenge lies in defining the factors controlling the permeability.

It is well known that the permeability of an individual pore is proportional to the square of its diameter, and numerous formulae have been proposed to estimate the permeability of a porous medium from its mean pore diameter (e.g. Carrier, 2003). The pore size distribution of a soil is often inferred from its particle size distribution. This is a practical approach for mineral soils as their particles consist of readilydefinable, individual grains. Permeability also depends on other pore properties such as their shape, number, orientation and continuity. Numerous theoretical and empirical attempts have been made to define the relation between permeability and these factors, often with the use of a single coefficient. For instance, Hazen (1911) suggested the approximation;

$K^{*}=c D^{2}$

where $c$ is a dimensionless coefficient representing the sphericity or roundness of the grains/pores; and $D[\mathrm{~L}]$ is the mean pore or grain diameter. The widely-used KozenyCarman equation (proposed by Kozeny, 1927 and later modified by Carman, 1937) also relies on a dimensionless coefficient to account for the grain/pore shape coefficient (Carrier, 2003):

$K^{*}=c \frac{D^{2} \phi^{3}}{(1-\phi)^{2}}$

where $\phi[-]$ is the water-filled porosity, $c[-]$ is the grain/pore shape coefficient, and $D[\mathrm{~L}]$ is the representative mean waterfilled pore or grain diameter.

The aforementioned formulae are all founded on the assumption that soil pores are circular in cross-section, and depend on a single empirical or theoretical coefficient to correct for the non-circularity of pores and other geometric pore properties, with the exception of their diameter which is inferred. This approach was necessary as the ability to visualise grains and pore spaces in detail was very limited. However, new visualisation techniques offer the opportunity to directly measure porous media properties that hitherto could be only be measured or derived theoretically. For example, a recent study on microscopic image analysis of peat thin sections related permeability to the measured geometric mean pore diameter, $d_{G}[\mathrm{~L}]$ :

$K^{*}=2 d_{G}^{2} / C$

where $C=2 / c$ is a dimensionless coefficient that relates a friction factor $(f)$ and the Reynolds' number $\left(N_{R}\right)$ in the wellknown Darcy Weisbach expression, $f=C / N_{R}$ (Quinton et al., 2000, Eq. 5). They found that when the saturated zone is confined within either the upper peat layer or the lower, more decomposed layer, $C$ tended to reasonably constant values equal to $C=\sim 300$ and $C=\sim 14500$ respectively. The large difference in $C$ confirmed that the larger-diameter soil pores of the living vegetation and lightly decomposed peat near the ground surface offer much less resistance to water motion than the finer-grained peat deeper in the profile. While this study directly measured pore size, it still relied on a coefficient to represent all other geometric pore properties.

A subsequent study directly measured pore cross-sectional areas and perimeters on microscopic images of peat thin sections, and from their ratio computed the hydraulic radius $R$ of all measured pores (Quinton et al., 2008). The authors used $R$ in the well-known Hagen-Poiseuille formula (White, 1974) to represent both pore size and shape in the estimation of permeability, and showed that its value decreases with depth below the ground as pores are compressed by the overlying sediments. By directly measuring pore shape and size, the dependence on a coefficient to define pore properties was reduced.

Image analyses of 2-D thin sections provides little information on unsaturated flow and storage processes, since all water is removed during sample preparation. However, Xray computed tomography (CT) imaging (Salem and Chilingarian, 1999) provides a new opportunity to evaluate the pore geometry of peat samples in 3-D. Kettridge and Binley (2008) examined the potential of using X-ray computed tomography to analyse individual biogenic gas bubbles entrapped within Sphagnum peats and to produce reliable descriptors for quantifying the structural properties of the peat. Because the method is non-destructive, the same peat sample can be re-scanned under different moisture contents. Coupling such scans with experimental measurements of unsaturated hydraulic conductivity using a constant-head permeameter offers the prospect of directly measuring geometric pore properties for peats of known hydraulic conductivity, and to evaluate the effect of these properties and moisture content on the pattern and rate of flow.

The objectives of this paper are to use high-resolution 3-D CT images of peat to: 1) evaluate the ability to quantify pore properties for different water contents; 2) characterise the soil pore properties known to control the value of the shape coefficients present in all classical expressions of permeability; and 3) test the sensitivity of pore-shape and 
geometry parameters on estimation of unsaturated hydraulic conductivity.

\section{Site description and methodology}

\subsection{Field sampling and preparation of peat in laboratory}

A $40 \times 40 \mathrm{~cm}$ peat block was removed from an undisturbed peat plateau at Scotty Creek $\left(61^{\circ} 18^{\prime} \mathrm{N} ; 121^{\circ} 18^{\prime} \mathrm{W}\right)$ in the wetland-dominated zone of discontinuous permafrost, $55 \mathrm{~km}$ south of Fort Simpson, Northwest Territories, Canada. At this site, the tree cover includes Picea mariana, Pinus contorta and Betula papyrifera. As with temperate peatlands and organic-covered permafrost terrains, Sphagnum mosses are the dominant peat-forming species on peat plateaus (Quinton et al., 2000). The sample block contained the upper peat layer extending to $20 \mathrm{~cm}$ depth, and was composed of living vegetation and lightly decomposed Sphagnum-peat, overlying a darker layer of peat in a more advanced state of decomposition. The peat block was refrigerated and transported to the Cold Regions Research Centre, Wilfrid Laurier University, Canada for sub-sampling.

In the laboratory, the peat block was saturated with water and then frozen, while in the same container that was used for transport. Once saturated and frozen, the block was then removed from the sample container, and three cylindrical subsample cores of $10 \mathrm{~cm}$ length and $6 \mathrm{~cm}$ diameter were extracted horizontally using a hollow drill bit mounted on a drill press. An upper, middle and lower core was extracted representing the $0-6 \mathrm{~cm}, 6-12 \mathrm{~cm}$ and $12-18 \mathrm{~cm}$ depth ranges. Each core was weighed and then inserted into a transparent acrylic tube ( $15 \mathrm{~cm}$ long, $6 \mathrm{~cm}$ inner-diameter) and allowed to thaw and freely drain for $48 \mathrm{~h}$. During this process, the sub-samples were covered with a plastic sheet to minimise evaporative losses of water. All subsequent measurements were based on the thawed sub-samples that remained in these tubes. The sub-samples were transported to the Department of Land Resource Science at the University of Guelph for hydraulic property measurements and CT scanning.

\subsection{Laboratory measurements of peat hydraulic properties}

In this experiment, the water content of the sub-sample was established by setting the heads (head is used to represent soil water pressure head) of the upper and lower clear Plexiglas pressure-plates, at fixed distances below the lower plate of the apparatus (Price et al., 2008). Each pressure-plate disc was perforated and had $25 \mu \mathrm{m}$ Nitex fabric glued to it to provide an air entry pressure of about $-40 \mathrm{~cm}$. The hydraulic gradient was established by setting a head difference between the outflow from the lower disc to the upper disc. The twin pressure plates maintained contact with the peat cores at both ends of the peat sample, and the average head
Table 1. Results of the volumetric water content $(\theta)$, flow rate $(Q)$, permeameter-based unsaturated hydraulic conductivity $(K)$, and sub-sample volume at ten head levels from saturation. The $K$ was calculated from equation 5 where the sub-sample cross sectional area $(A)$ was $28.3 \mathrm{~cm}^{2}\left(A=\pi r^{2}, r=3 \mathrm{~cm}\right)$ and the hydraulic gradient was $(\Delta h / \Delta L)=0.21$. The saturated hydraulic conductivity (pressure head $=0$ ) was derived from the field and laboratory measurements of Quinton et al. (2008).

\begin{tabular}{lcccl}
\hline $\begin{array}{l}\text { pressure } \\
\text { head } \\
(\mathrm{cm})\end{array}$ & $\begin{array}{c}\theta \\
\left(\mathrm{cm}^{3} / \mathrm{cm}^{3}\right)\end{array}$ & $\begin{array}{c}Q \\
(\mathrm{ml} / \mathrm{s})\end{array}$ & $\begin{array}{c}K \\
(\mathrm{~cm} / \mathrm{s})\end{array}$ & $\begin{array}{l}\text { sub- } \\
\text { sample } \\
\text { volume } \\
\left(\mathrm{cm}^{3}\right)\end{array}$ \\
\hline 0 & & & & 271.43 \\
-2 & 0.860 & - & 0.0670 & 271.43 \\
-6 & 0.668 & 0.05152 & 0.0087 & 259.72 \\
-10 & 0.616 & 0.02537 & 0.0043 & 256.99 \\
-14 & 0.552 & 0.00944 & 0.0016 & 256.99 \\
-18 & 0.492 & 0.00450 & 0.0007 & 254.25 \\
-22 & 0.457 & 0.00221 & 0.0003 & 245.71 \\
-26 & 0.429 & 0.00146 & 0.0002 & 245.71 \\
-30 & 0.412 & 0.00101 & 0.0001 & 237.31 \\
-40 & 0.390 & 0.00062 & 0.0001 & 237.31 \\
\hline
\end{tabular}

of the upper and lower discs was set at $-2,-6,-10,-14$, $-18,-22,-26,-30$ and $-40 \mathrm{~cm}$. At each average head, all measurements (i.e. unsaturated hydraulic conductivity, volumetric moisture content, bulk density, total porosity, volume) were made. At five of the steps $(-2,-10,-18,-30$, $-40 \mathrm{~cm})$, the CT scans were carried out before moving on to the next head level.

The unsaturated hydraulic conductivity of peat subsamples was measured experimentally using the constant head permeameter which is based on steady-state flow (Elrick and Reynolds, 1992). In this method, the volume flux through the unsaturated peat was measured $\left(Q\left[\mathrm{~L}^{3} \mathrm{~T}^{-1}\right]\right)$. The unsaturated hydraulic conductivity was calculated by applying Darcy's law as (Elrick and Bowman, 1964 and Price et al., 2008):

$K=\frac{Q}{A\left(\frac{\Delta h}{\Delta L}\right)}$

where $A\left[\mathrm{~L}^{2}\right]$ is the cross sectional area of sub-sample, $\Delta h[\mathrm{~L}]$ is the head difference across the sub-sample length $(=2 \mathrm{~cm}), \Delta L[\mathrm{~L}]$ is the length of sub-sample, and $(\Delta h / \Delta L)$ is the hydraulic gradient. The measured unsaturated hydraulic conductivities of the lower core sub-samples at 12 $18 \mathrm{~cm}$ depth range at nine different applied heads are shown in Table 1.

The sub-samples were weighted at each head, and these values were used in the calculation of volumetric water content (Gardner, 1986). The dry-weight of each sub-sample was measured after drying in an oven at $80^{\circ} \mathrm{C}$ for a period of a week, after the scanning was completed. The height and 
diameter of the sub-samples were measured after each head level change. The base volume of peat sub-samples was continuously decreased due to the shrinkage as the sub-samples dried, from about 1 to $5 \%$ in the tested range. During the first stage of drainage, the volume change was primarily vertical, thereafter becoming triaxial. Thus, peat bulk volume changes due to soil shrinkage must be taken into consideration in order to characterize accurately the bulk density and volumetric water content measurements. The volumetric water content and the volume of the lower core sub-sample at each head level are presented in Table 1.

Bulk density and total porosity of each sub-sample were gravimetrically determined at each soil-water head following the method of Boelter (1976) based on the original subsample volume, the sub-sample mass at specified head intervals and the dry mass. The measured bulk density of the sub-samples was $0.035,0.054$ and $0.071\left(\mathrm{~g} \mathrm{~cm}^{-3}\right)$ and the measured total porosity was $0.955,0.863$, and 0.933 for the upper, middle and lower cores respectively. The volume fraction of air bubbles of these sub-samples was computed in Quinton et al. (2009) as 0.125, 0.077, and 0.106 for the upper, middle and lower cores, respectively.

\subsection{3-D X-ray CT imaging acquisition and processing}

Each sub-sample was scanned at heads of $-2,-10,-18$, -30 and $-40 \mathrm{~cm}$, for a total of 15 scans using an X-ray MicroCT scanner. Upon reaching these head levels, the subsample tubes were disconnected from the pressure plates and inserted into an X-ray CT scanner. The scans were made using a GE Medical $\mu \mathrm{CT}$, model MS8X-130, source with $130 \mathrm{kVp}$ monochromatic X-ray beam at $100 \mathrm{kV} 80 \mathrm{~mA}$, 3500 millisecond exposure with a high pass filter to reduce hardening artefacts, and enhance contrast between sample phases. The detector was a high resolution digital X-ray camera detector system. This detector accumulates all the energy of the transmitted photons and provides the numerical data to be used in reconstructing an image. For each head, 720 views of the sub-sample were taken at half angle increments over $360^{\circ}$. Once the scans were finished the collected raw data (the series of rotational X-ray images) were reconstructed with an ultra-high resolution noise-reducing filtered back-projection algorithm (Lewitt, 1983) to derive images with good contrast between the two phases - air-filled pores and the combined water and organic material. The resulting 3-D imagery was acquired at size of $1350 \times 1350 \times 876$ voxels in a local 3-D (XYZ) coordinate system with a resolution of $0.045 \times 0.045 \times 0.045 \mathrm{~mm}$ for each voxel. In order to reduce inherent noise and partial volume effects that are present in X-ray CT data, a noise reducing homomorphic filter and threshold determination technique was employed (Elliot and Heck, 2007). After each scan, the peat sub-sample tubes were reconnected to the twin pressure plates and the next head level was established. The analyses of 3-D image were conducted on the subsequently cropped images with a

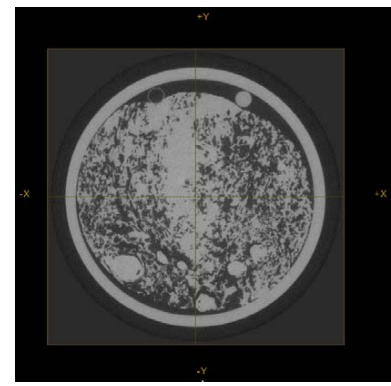

(a)

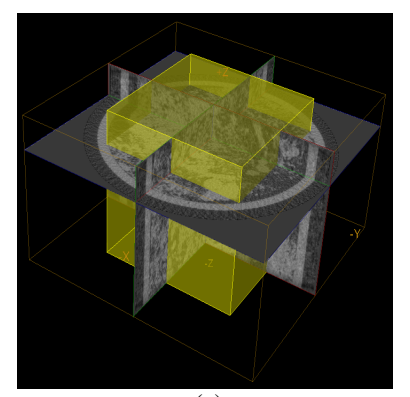

(c)

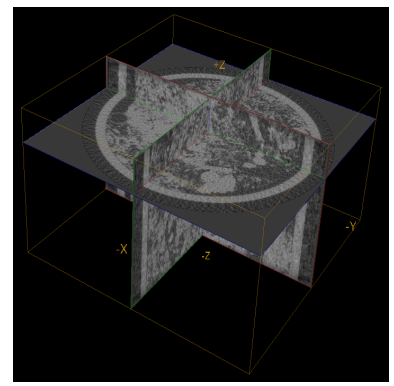

(b)

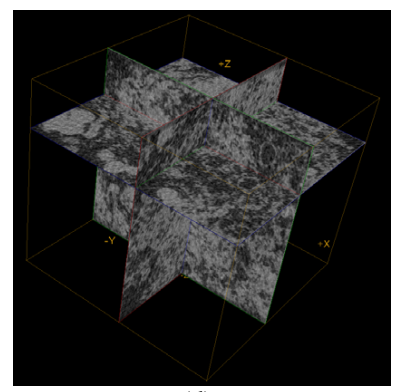

(d)
Fig. 1. (a) Pore space in 2-D section of the acquired image by CT, (b) 3-D view of the pore space, (c) selecting a 3-D cuboid region of interest, and (d) 3 -D cropped image with a size of $900 \times 900 \times 720$ voxels. The dark part represents the air-filled pore spaces and the light part represents the water plus organic material spaces.

size of $900 \times 900 \times 720$ voxels (volume of $53.14 \mathrm{~cm}^{3}$ ); this resulted in $\sim 600$ million voxels for each data set. An example of 2-D and 3-D, CT images rendering of the pore spaces and selecting a region of interest are shown in Fig. 1.

High-resolution X-ray CT offers a unique opportunity to observe pore distribution on a scale useful for analysis. In $3-\mathrm{D}$, a pore is a connected cluster of voxels, limited by at least two boundaries at the border of the solid space. The total volume of the pores filled with air (void space) or airfilled porosity can be calculated from the $\mathrm{CT}$ image of the peat sub-sample by detecting the air-filled pore spaces using image segmentation techniques where the air-filled porosity of peat is the ratio between the volume of empty space and the total volume of the peat sub-sample. Segmentation is the first treatment applied to CT images before analysing the pore distribution. This step is crucial because of the nature of the CT image and the sensitivity of image segmentation techniques. It can reduce or increase the estimate of pore space and blur or make an apparent connection between them. The properties of the feature resulting from the segmented image can vary greatly with small changes in the segmentation parameters (Taud et al., 2005). Linear attenuation coefficients are collected during scanning and are transformed to a standardized CT measure, the Hounsfield Units (HU), which assigns to each voxel an intensity value between -1500 and 1000 . High CT numbers correspond 
to high density materials. The large density difference between air $(\mathrm{HU}=-1000)$, represented by void voxels, and the remaining constituents of water and organic solids $(\mathrm{HU}=\sim 0)$ represented by the non-void voxels, allows direct imaging of individual pores and networks.

In order to separate void (air-filled pores) from the solid matrix (organic material and water), a new neighbourhoodbased standard deviation thresholding algorithm (Elliot and Heck, 2007) was applied for CT images at specific head levels. This method is a quantitative approach for selecting a threshold that involves fitting a Gaussian distribution to a bimodal distribution on a histogram of relative density for the sub-sample. In this technique, the original grey-level microtomographic images were processed using ImageJ software (Rasband, 2005) to produce binary images after segmentation of the air-filled pores and solid phases. This procedure is based on the grey-level histogram, where the user applies a threshold value determined by the Elliot and Heck (2007) method, which operates on the equi-probability point that separates the grey level classes associated with solid and voids. The histogram in Fig. 2 describes the CT numbers and their frequency distribution for each head level and indicates that air is the easiest to discern in the images, but water, solid and organic compounds are not discernable from each other. As the head decreased and water drained from the samples, the histogram (Fig. 2) was redistributed such that the area below the curve representing the void voxels increased proportionately with a decrease in area below the curve representing the non-void voxels. Fig. 2 also shows some slight lateral shift of the "solid-phase" histogram peak among the head levels, which is an artefact of the partial-volume influence and highly-intermixed water-organic component of the peat. However, the threshold determination is performed individually for each scan, and was not influenced by this shift. In this study, the solid and liquid fractions of the histograms presented in Fig. 2 were not separated, as there is at present no effective algorithm that could segment out the organic peat (inclusive of hyaline cells) from the surrounding water with a degree of verisimilitude. Therefore, the non-void voxels represent the solid fraction, the water imbibed within it, and the water occupying the active porosity (Quinton et al., 2009).

The most accessible measurement from MicroCT binary images includes the geometry and structure of air-filled pores (voids) which is simply a count of black voxels in a subsample volume (Fig. 1). Using a 3-D digital image analysis technique, the pore distribution through the peat subsample was quantified. The morphology of air-filled pores was measured by a "3-D Objects Counter" algorithm in ImageJ (Rasband, 2005). This algorithm establishes the presence of discrete structures in 3-D binary imagery, and subsequently counts the number of structures and quantifies some morphology characteristics of the separable structures. The threshold value was adjusted for each CT image at each head level through this process.

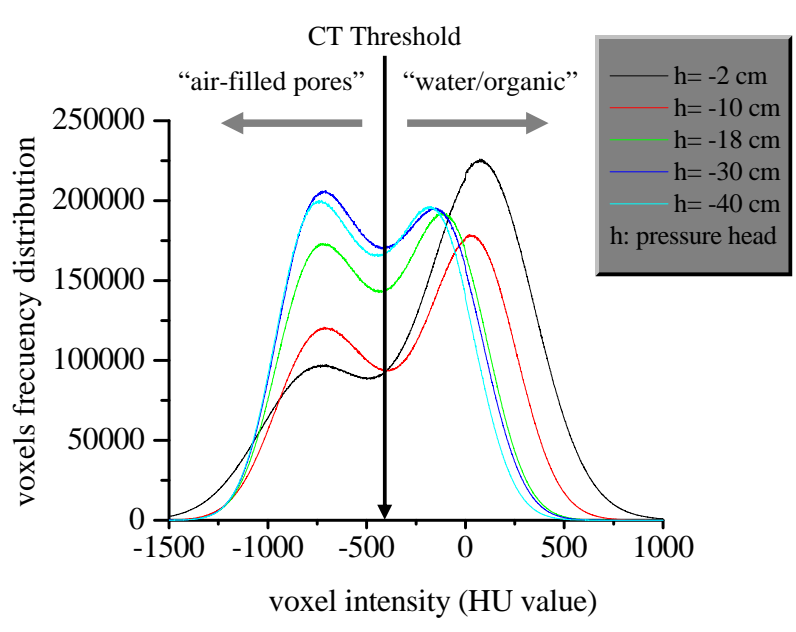

Fig. 2. Histograms of voxel intensity in Hounsfield Units (HU) for each head level applied to the peat sub-sample.

\section{Results and discussion}

\subsection{Evaluation of CT to quantify geometric pore properties}

The focus of the analyses was upon the upper peat layer, since it is this layer that conducts most of the drainage during the spring freshet (Quinton et al., 2000). We extracted the cores horizontally because the vertical travel time of water is so short due to the very high infiltration rates and the short travel distance between the ground surface and water table. Therefore, it is the horizontal pathway that controls the overall travel time from the time of infiltration to the time that water arrives to the base of a hillslope. An initial analysis of the three peat sub-samples (upper, middle and lower cores) taken from the upper peat layer indicated little variation among them in terms of their physical and hydraulic properties. As a result, only one sub-sample was used for detailed analysis. The lower core was selected for this purpose because it is closer to the relatively impermeable frost table for the first several weeks of soil thaw, and therefore conducts runoff during the time when the majority of the annual subsurface runoff is conveyed through the peat. The summary results of 3-D analysis of 3-D images of this sub-sample core at five levels of hydraulic head are shown in Table 2. The airfilled porosity $\left(\phi_{a}\right)$ was computed as the ratio between the total volume of empty pores and the total volume of the peat sub-sample $\left(V_{\text {img }}\right)$;

$\phi_{a}=\sum_{i} V_{i} / V_{\mathrm{img}}$

where $V_{i}\left[\mathrm{~L}^{3}\right]$ is the volume of the $i$-th pore on all $900 \times 900 \times 720$ voxels.

To determine an equivalent pore radius for the complex geometries of 3-D pores that cannot be adequately represented 
Table 2. Summary results of analysis of 3-D images to measure the air-filled pore size distribution at five head levels: the air-filled porosity $\left(\phi_{a}\right)$, total counted number of air-filled pores within sub-sample volume, number of air-filled pores per $\mathrm{cm}^{3}$, percentage of $\phi_{a}$ occupied by the largest pore, radius factor $\left(R_{p}\right)$ of largest pore, and the average pore tortuosity, $\bar{\tau}_{p}$. The sub-sample volume was $53.14 \mathrm{~cm}^{3}(900 \times 900 \times 720$ voxels).

\begin{tabular}{lllllll}
\hline $\begin{array}{l}\text { pressure head } \\
(\mathrm{cm})\end{array}$ & $\begin{array}{l}\phi_{a} \\
(\%)\end{array}$ & $\begin{array}{l}\text { total number } \\
\text { of pores }\end{array}$ & $\begin{array}{l}\text { number of } \\
\text { pores }\left(\text { per } \mathrm{cm}^{3}\right)\end{array}$ & $\begin{array}{l}\text { largest pore } \\
\left(\% \text { of } \phi_{a}\right)\end{array}$ & $\begin{array}{l}\text { radius factor } \\
\left(R_{p}\right) \text { of largest } \\
\text { pore }(\mathrm{cm})\end{array}$ & $\begin{array}{l}\bar{\tau}_{p} \\
(-)\end{array}$ \\
\hline-2 & 28.4 & 1985 & 37 & 94.86 & 2.15 & 1.96 \\
-10 & 40.3 & 2791 & 52 & 98.36 & 2.28 & 3.06 \\
-18 & 46.2 & 3833 & 72 & 99.67 & 2.32 & 3.82 \\
-30 & 49.9 & 7827 & 147 & 99.78 & 2.35 & 4.13 \\
-40 & 52.9 & 5901 & 111 & 99.82 & 2.36 & 4.38 \\
\hline
\end{tabular}

as a spherical or cubic shape, we defined a pore radius factor $\left(R_{p}\right)$ to assess and quantify the geometry of opening surfaces (Milne et al., 1996; Wang et al., 2007). The $R_{p}[\mathrm{~L}]$ equals half the maximum harmonic average radius $R_{\text {har }}[\mathrm{L}]$ of a surface (measured from the centre of the pore). The $R_{\text {har }}$ is defined as the harmonic average distance from a point on the centre of the pore to the abutments as:

$$
R_{\mathrm{har}}=\frac{1}{\frac{1}{n} \sum_{\theta=1}^{n} 1 / r_{\theta}}
$$

where $r_{\theta}[\mathrm{L}]$ is the distance from any point on a pore surface to the abutments at angle $\theta$ and $n$ is the number of rays measured to the surface edge or abutment. $R_{\text {har }}$ has a maximum value towards the centre of the pore and decreasing values towards the edges. The $R_{p}$ is calculated at the centre of the surface and corresponds to the location with the largest $R_{\text {har }}$ value as $R_{p}=(1 / 2) \operatorname{Max}\left(R_{\mathrm{har}}\right)$.

The tortuosity of each pore $\left(\tau_{p}[-]\right)$ was calculated as a function of air-filled porosity (Berryman and Blair, 1987) by:

$$
\tau_{p}=\frac{\phi_{a} A_{p}}{\pi R_{p}^{2}},
$$

where $\phi_{a}$ is the air-filled porosity of the sub-sample, $A_{p}$ is the pore surface area, and $R_{p}$ is the pore radius factor calculated between 0.001 to $2.36 \mathrm{~cm}$ using Eq. (7). There was a general increase in air-filled porosity, the percentage of $\phi_{a}$ occupied by the largest pore, and the average pore tortuosity as the volumetric moisture content decreased with a decrease in head (Table 2). Results show that a considerable increase in the number of air-filled pores was detectable with a decrease in head because the number of pores that were once saturated in the wetter sub-sample had now drained and filled with air as the hydraulic head decreased. At low heads the distribution of pores is skewed, with the number of pores decreasing as their size increases. As the air-filled pore size increases, its shape becomes elongated and connects with other pores.
In our previous paper (Quinton et al., 2009), we found that the distribution of pore size in 3-D measurements is dominated by a single large pore, whose volume and surface area is 3-orders of magnitude larger than the next largest pore (Figs. 3 and 4 in Quinton et al., 2009). This single large pore is readily observed as the interconnected pore space that extends throughout the peat sub-sample. The dominance of this single large pore-space was found at all five head levels, where it accounted for $>94-99 \%$ of the air-filled porosity (Table 2). There was a general increase in the radius factor corresponding to the increase of the single large airfilled pore volume with decreased head. Once the head decreased, the radius factor for the single large air-filled pore increased $\sim 10 \%$ in the sub-sample (Table 2 ). A large number of smaller air-filled pores also exist in the sample, and probably contribute to the obstruction of flow as they are disconnected and are more tortuous than the single large airfilled pore. Therefore, this single large pore imparted a more effective flowpath, when it is saturated, compared to smaller pores and higher resistance to flow, when it is unsaturated, due to a larger air-filled pore space. Although smaller pores may contribute to the obstruction of flow, their contribution to flow may be neglected when a very large pore is active.

It can be assumed at the lowest applied head $(-40 \mathrm{~cm})$, most of the pore space is air-filled and the air-filled porosity is essentially the active porosity ( $\sim 60 \%$, reported by Hoag and Price, 1997; Quinton et al., 2000). Table 2 shows that the radius factor of the single large air-filled pore increased $\sim 2 \%$ between pressure head from $-18 \mathrm{~cm}$ to $-40 \mathrm{~cm}$. This small change in the single large air-filled pore size at lower pressure heads can be described with an increase in draining of the smaller pores, as the air-filled porosity increases. An air-filled porosity of approximately 53\% (see Table 2, head $=-40 \mathrm{~cm}$ ) is reasonable given that the difference between it and the measured total porosity of $\sim 93 \%$, is accounted for by the sum of the inactive porosity, which is typically $\sim 20 \%$ (e.g. Hoag and Price, 1997); and a residual of $\sim 20 \%$ that would be accommodated in the sample at the $-40 \mathrm{~cm}$ by the water held in the remaining films and the 
volume fraction of air bubbles $(\sim 11 \%$, reported by Quinton et al., 2009).

Three dimensional CT digital image analysis of peat samples showed that the pore structure and configuration of peat soils are very complex and contains many variables. Therefore, we used this technique as an opportunity to quantify and directly measure the size and geometry properties of the pores and thereby to determine the shape and tortuosity factors of the pores which control the permeability and unsaturated hydraulic conductivity estimation.

\subsection{Characterization of pore properties to control the pore shape coefficient $(c)$}

Since the permeability measures the viscous resistance of the porous media to fluid flowing through its pores, permeability would be expected to correlate with the amount of surface area and volume of the pores (Schlueter et al., 1997). In peat soils, defining the dimensionless constant pore shape coefficient $c$ (Eq. 2) is difficult because of the highly irregular shape of pores in peat soils that has some influences on the rate of flow through peat. The coefficient $c$ usually includes properties such as pore path tortuosity, number of air-filled pores, the pore sphericity or roundness of the pores. Marshall (1958) developed a theory to include soils with distributions of pore size and obtained an expression where unsaturated permeability decreases with a increase in the number of pores $(N)$ and a decrease in their radius $(r)$ (i.e. $K^{*} \propto 1 / N^{2}$ and $\left.K^{*} \propto r^{2}\right)$. We used this expression for defining the $c$. The coefficient $c$ often referred to as the shape coefficient, was computed from morphological characteristics of the pores:

$c=\left(\frac{S_{p}}{N^{2} \times \tau_{p}}\right)$

where $S_{p}[-]$ is the pore sphericity and $\tau_{p}[-]$ is the pore path tortuosity (Eq. 8 ). The $S_{p}$ can be calculated by:

$S_{p}=\frac{\pi^{1 / 3}\left(6 V_{p}\right)^{2 / 3}}{A_{p}}$

where $V_{p}$ and $A_{p}$ are the pore volume and surface area, respectively (Wadell, 1935). Tortuosity is based on the fact that pores are irregular and upon drying, water will concentrate in small angles and crevices of the pore system as water films. The connectivity of the pore space has proved to play an important role in soil hydraulic properties and in its hysteretic behaviour; however, a quantitative morphological description of the connectivity of the complex porous structure in peat soil is difficult. Tortuosity is one of the most meaningful 3-D parameters of pore structure, which expresses the degree of complexity of the sinuous pore path. Tortuosity can easily be related to the conductivity of a porous medium since it provides an indication of increased resistance to flow due to the pore system's greater path length; i.e. an increased path length results in less connection or reduced hydraulic conductivity (Dullien, 1979; Vogel, 1997). Equations (9) and (10) evaluate our CT measurements of the pore properties that control the shape coefficient $c$ which affect the hydraulic properties related to water transport and storage. The pore shape coefficient is therefore important for evaluating and calculating the permeability and hydraulic conductivity of peat soils.

\subsection{Factors controlling the permeability and unsatu- rated hydraulic conductivity estimation}

The main factors affecting hydraulic conductivity are the shape, interconnectivity (i.e. tortuosity), porosity and the hydraulic radius of pores. The pore properties and pore shape coefficient derived above can be used to give an estimate of permeability using the Hazen (Eq. 2) and KozenyCarman (Eq. 3) relations. These two equations were developed to estimate the permeability under saturated conditions since both of these equations use the water-filled pore size distribution. To use these equations in unsaturated conditions, the water-filled pores are the conducting pores and those filled with air are excluded from the calculation so that $\phi$ and $D$ should be replaced by the remaining water-filled volume and pore radius, respectively. Therefore, a modification is suggested to account for this in which both air-filled pore geometry and porosity are taken into account. We have modified the Hazen and Kozeny-Carman's formulae (Eqs. 2 and 3 ) to estimate the pore permeability. The modified equation for the Hazen relation is defined as:

$K_{p}^{*}=c\left(R_{p}^{\prime}-R_{p}\right)^{2}$

and modified Kozeny-Carman equation is defined as:

$K_{p}^{*}=c \frac{\left(R_{p}^{\prime}-R_{p}\right)^{2}\left(\phi_{T}-\phi_{a}\right)^{3}}{\left(1-\left(\phi_{T}-\phi_{a}\right)\right)^{2}}$

where $K_{p}^{*}$ is the unsaturated pore permeability, $c$ is the pore shape coefficient, $R_{p}$ is the pore radius factor, $\phi_{a}$ is $\phi_{T}$ the air-filled porosity, $\phi_{T}$ is the total porosity (was measured using gravimetric method as 0.933 ) and $R_{p}^{\prime}$ is the maximum water-filled pore radius factor of the largest pore (measured at the lowest head near to active porosity) where $R_{p}^{\prime}>R_{p}$. The average pore permeability was used to estimate the unsaturated hydraulic conductivity using Eq. (1). As the peat drains (i.e. when the head decreases), the first pores to release water are the largest ones. Any remaining air-filled pores are bypassed, and tortuosity is increased. Equations (9), (11) and (12) show that a change in the number, volume and tortuosity of air-filled pores varies the permeability of peat. This shows the sensitivity of pore shape coefficient and geometry parameters on estimation of unsaturated hydraulic conductivity. Table 3 shows the results of unsaturated hydraulic conductivity measured from permeameter analysis and estimated from the shape and size distribution of pores at different water head levels. The estimated unsaturated hydraulic 
Table 3. Unsaturated hydraulic conductivity $(\mathrm{cm} / \mathrm{s})$ measured by a experimental method (permeameter) and estimated by two calculations (modified Hazen, and modified Kozeny-Carmen) at different head levels.

\begin{tabular}{clll}
\hline \multirow{2}{*}{ pressure head $(\mathrm{cm})$} & experiment & \multicolumn{2}{c}{ estimation } \\
\cline { 2 - 4 } & permeameter & \multicolumn{2}{c}{ pore size analysis } \\
\cline { 3 - 4 } & & modified & \multicolumn{1}{c}{ modified } \\
& & Hazen & $\begin{array}{l}\text { Kozeny- } \\
\text { Carman }\end{array}$ \\
\hline-2 & 0.0087 & 0.0072 & 0.0057 \\
-10 & 0.0016 & 0.0021 & 0.0014 \\
-18 & 0.0003 & 0.0009 & 0.0003 \\
-30 & 0.0001 & 0.0002 & 0.000057 \\
-40 & 0.000057 & 0.000038 & 0.000071 \\
\hline
\end{tabular}

conductivities from pore size analysis were very close to the experimental values measured with a standard permeameterbased method. Results in Table 3 show that as soon as water content decreases (i.e. when the absolute value of the head decreases), the estimated hydraulic conductivity drops by a similar amount to the measured change. The explanation is that the set of water-filled pores in the sample becomes rapidly disconnected and hence the rate of flow decreased.

The unsaturated hydraulic conductivity at various heads (Fig. 3) shows that the rapid initial drainage creates a sharp decline in hydraulic conductivity, decreasing by one to two orders of magnitude. Since large pores readily lose water, the peat rapidly becomes less conductive and the flow path among pores, more tortuous. Variability in hydraulic conductivity was found to be relatively small at intermediate and high head levels. The validity of peat unsaturated hydraulic conductivity estimations were tested by making a comparison with measured standard permeameter-based method. The hydraulic conductivity computed using CT measured values of the pore properties controlling the coefficient $c$, closely matched the measured hydraulic conductivity values (Fig. 4). This suggests that the CT scan method successfully measured the key pore properties controlling the coefficient $c$; therefore the 3-D high resolution computed tomography imagery provides a direct method to determine the geometric pore properties and thereby determines the shape and tortuosity factors of the pores which control the permeability and unsaturated hydraulic conductivity estimation.

\section{Conclusions}

The classical permeability equations express strong dependence of permeability on the pore shape coefficient with the assumption that soil pores are circular in cross-section, and depend on an empirical or theoretical coefficient to correct for the non-circularity of pores and other geometric pore

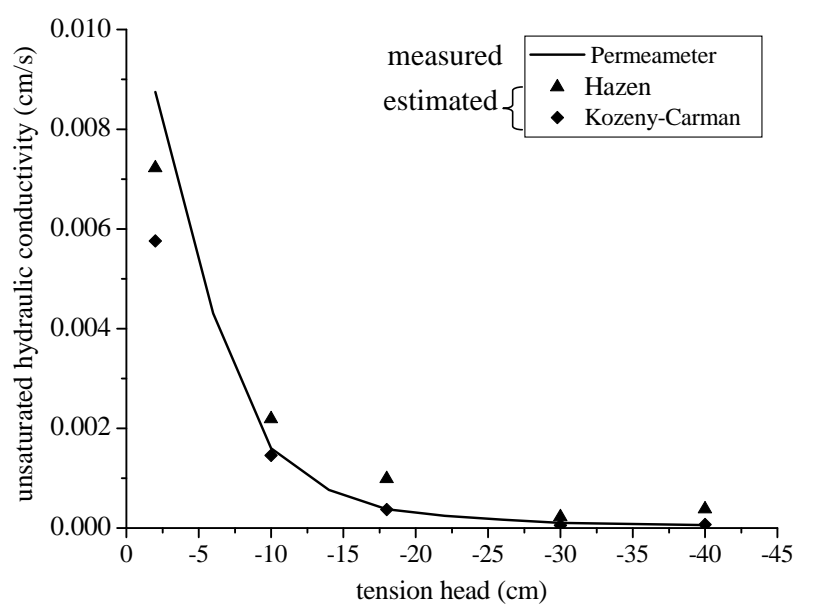

Fig. 3. Unsaturated hydraulic conductivity versus head of peat soil obtained by an experimental measurement from a permeameter apparatus and two indirect estimations from modified Hazen and modified Kozeny-Carman equations.

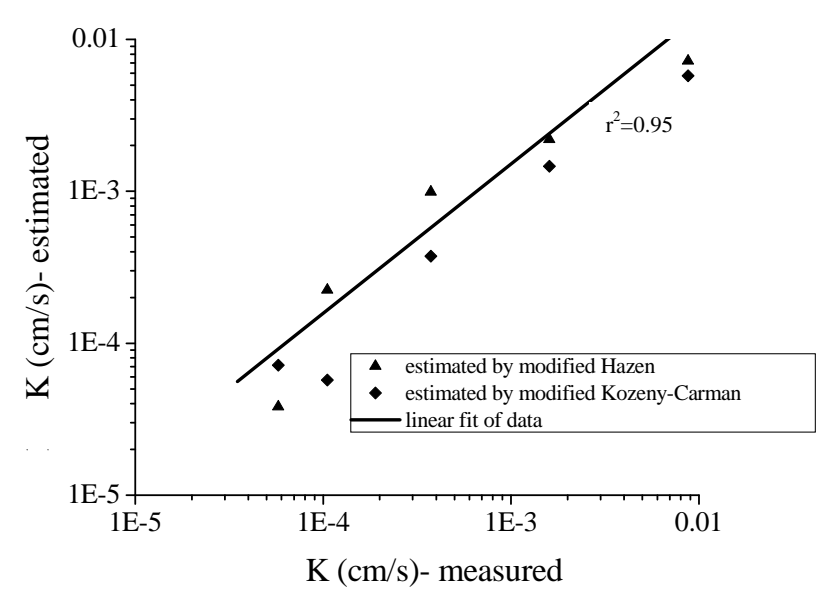

Fig. 4. Comparison of the values of measured unsaturated hydraulic conductivity with those estimated from two modified equations. Agreement between estimated and measured values was satisfactory with a linear relationship and regression coefficient of 0.95 .

properties. In fact, this is true for general porous media (i.e. sands or mineral soils). However, in peat soils in which pore distribution is dominated by a single large pore-space and have highly irregular shape of pores, this assumption is not reasonable. As the pore structure and configuration of peat soils are very complex and contains many variables, the hypothesis that pore properties control the pore shape requires high resolution consideration. The 3-D computed tomography imagery provided a direct method to determine the geometry of the pores and flow paths and thereby enables direct calculations of the shape and tortuosity factors. In this study, we investigated how the shape, interconnectivity (i.e. tortuosity), percentage (i.e. porosity), and the hydraulic 
radius of the pores, derived by direct measurements of the pore properties using 3-D high resolution images, affected the hydraulic conductivity of peat soils. The pore properties of unsaturated peat were used to demonstrate how they control the pore shape coefficient and were then used to make quantitative estimations of the unsaturated hydraulic conductivity. Estimates of unsaturated hydraulic conductivities made for the purpose of testing the sensitivity of pore-shape and geometry parameters on hydraulic properties of peats were used to evaluate how the structure of the peat affects its parameterization. Unsaturated hydraulic conductivity of peat was estimated using two modified equations (KozenyCarman and Hazen). The validity of our estimations was tested by making a comparison with standard permeameterbased measurements. The estimates agree very well with measured unsaturated hydraulic conductivity which indicates that our direct measurement of the peat pore properties using 3-D CT images that control the shape coefficient are realistic.

This study suggests that hydraulic conductivity of peat soils is essentially controlled by a pore shape coefficient, which is usually assumed to include properties such as path tortuosity, pore size distribution, the sphericity and roundness of the pores. Therefore, a method of analysis was developed to emphasize the role of the pore shape on physical and hydraulic properties. This novel approach is restricted to peat soils used in this study for the range of soil moisture levels that typically occur at the field site over a year. In order to apply this method of analysis, it is necessary to have a reliable direct measurement of pore properties and shape coefficient of pores, since this can now be done by high resolution, 3-D imagery. The availability of 3-D computer tomographic imaging provides a new opportunity to evaluate the 3-D pore geometry and its role in defining fundamental hydraulic properties of peat.

Acknowledgements. This research was funded by the Canadian Foundation for Climate and Atmospheric Sciences (IP3 Research Network), the Natural Sciences and Engineering Research Council, and the International Polar Year. The authors thank P. Whittington and Trevor Myers for their assistance with obtaining peat samples in the field, conducting the CT scans and providing the images. We gratefully acknowledge the Aurora Research Institute for their assistance in obtaining a research license (\#13786). We also wish to thank the Jean-Marie River First Nation, the Denedeh Resources Committee, Deh Cho First Nation, Fort Simpson Métis Local \#52, Liidlii Kue First Nation and the Village of Fort Simpson for their support of this project.

Edited by: S. Carey

\section{References}

Beckwith, C. W., Baird, A. J., and Heathwaite, A. L.: Anisotropy and depth related heterogeneity of hydraulic conductivity in a bog peat. I: laboratory measurements, Hydrol. Process., 17, 89101, 2003.

Berryman, J. G. and Blair, S. C.: Kozeny-Carman relations and image processing methods for estimating Darcy's constant, J. Appl. Phys., 63, 2221-2228, 1987.

Boelter, D. H.: Methods for analysing the hydrological characteristics of organic soils in marsh-ridden areas, in: Hydrology of Marsh-Ridden Areas, Proceedings of IASH Symposium Minsk, 1972, IASH, UNESCO, Paris, 161-169, 1976.

Carman, P. C.: Fluid flow through Granular Beds, Trans. Inst. Chem. Eng., 15, 150-166, 1937.

Carman, P. C.: Flow of Gases through Porous Media, Butterworths Scientific Publications, London, 1956.

Carrier, W. D.: Goodbye, Hazen; Hello, Kozeny-Carman, J. Geotech. Geoenviron., 129, 11, 1054-1056, 2003.

Dullien, F. A. L.: Porous media- flow transport and pore structure, 2nd Edn., Academic Press, New York, 1979.

Elliot, T. R. and Heck, R. J.: A comparison between 2D vs 3D thresholding of X-ray CT imagery, Can. J. Soil Sci., 84, 4, 405412, 2007.

Elrick, D. E. and Bowman, D. H.: Note on an improved apparatus for soil moisture flow measurements, Soil Sci. Soc. Am. Proc., 28, 450-453, 1964.

Elrick, D. E. and Reynolds, W. D.: Infiltration from constant-head well permeameters and infiltrometers, in: Advances in Measurement of Soil Physical Properties: Bringing Theory into Practice, edited by: Topp, G. C., Reynolds W. D., and Green, R. E., Soil Science Society of America, Madison, WI, Special Publication No. 30, 1-24, 1992.

Gardner, W. H.: Water Content, in: Methods of Soil Analysis: Physical and Mineralogical Methods, edited by: Kiute, A., Agronomy Series 9 (Part 1), Soil Science Society of America, Madison, Wisconsin, 493-544, 1986.

Hazen, A.: Discussion of "Dams on sand formations" by A. C. Koenig., Transactions of the American Society of Civil Engineers, 73, 199-203, 1911.

Hoag, R. S. and Price, J. S.: A field-scale, natural gradient solute transport experiment in peat at a Newfoundland blanket bog, J. Hydrol., 172, 171-184, 1995.

Hoag, R. S. and Price, J. S.: The effects of matrix diffusion on solute transport and retardation in undisturbed peat in laboratory columns, J. Contam. Hydrol., 28, 193-205, 1997.

Hubbert, M. K.: Darcy's law and the field equations of the flow of underground fluids, Petroleum Transaction, Amer. Inst. Min. Mandal Eng., 207, 222-239, 1956.

Kozeny, J.: Über Kapillare Leitung Des Wassers in Boden, Sitzungsber. Akad. Wiss. Wien, Math. Naturwiss. Kl., Abt. 2a, 136, 271-306, 1927.

Kettridge, N. and Binley, A.: X-ray computed tomography of peat soils: measuring gas content and peat structure, Hydrol. Process., 22, 4827-4837, 2008.

Lewitt, R. M.: Reconstruction algorithms: Transform methods, in: Proc. IEEE, 71, 390-408, 1983.

Marshall, T. J.: A relation between permeability and size distribution of pores, J. Soil Sci., 9, 1-8, 1958. 
Milne, D. M., Pakalnis, R. C., and Lunder, P. J.: Approach to the quantification of hangingwall behaviour, Trans. Inst. Min. Metall., 105, A69-A74, 1996.

Price, J. S., Whittington, P. N., Elrick, D. E, Strack, M., Brunet, N., and Faux, E.: A Method to Determine Unsaturated Hydraulic Conductivity in Living and Undecomposed Sphagnum Moss, Soil Sci. Soc. Am. J., 15, 487-491, 2008.

Quinton, W. L., Gray, D. M., and Marsh, P.: Subsurface drainage from hummock-covered hillslope in the Arctic tundra, J. Hydrol., 237, 113-125, 2000.

Quinton, W. L. and Hayashi, M.: The flow and storage of water in the wetland-dominated central Mackenzie Rriver basin: Recent advances and future directions, in: Prediction in ungauged basins: Approaches for Canada's cold regions, edited by: Spence, C., Pomeroy, J. W., and Pietroniro, A., Canadian Water Resources Association, 45-66, 2005.

Quinton, W. L., Hayashi, M., and Carey, S. K.: Peat Hydraulic Conductivity in Cold Regions and its Relation to Pore Size and Geometry, Hydrol. Process., 22, 2829-2837, 2008.

Quinton, W. L., Elliot, T., Price, J. S., Rezanezhad, F., and Heck, R.: Measuring Physical and Hydraulic Properties of Peat from X-ray Tomography, Geoderma, 153, 269-277, 2009.

Rasband, W.: ImageJ, Image Manipulation Software. National Institute of Health, Bethesda, MD, USA, available at: http://rsb. info.nih.gov/ij/, 2005.
Salem, H. S. and Chilingarian, G. V.: Determination of specific surface area and mean grain size from well-log data and their influence on the physical behavior of offshore reservoirs, J. Petrol. Sci. Eng., 22, 241-252, 1999.

Schlueter, E. M., Zimmerman, R. W., Witherspoon, P. A., and Cook, N. G. W.: The fractal dimension of pores in sedimentary rocks and its influence on permeability, Eng. Geol., 48, 199-215, 1997.

Taud, H., Martinez-Angeles, R., Parrot, J. F., and HernandezEscobedo, L.: Porosity estimation method by X-ray computed tomography, J. Petrol. Sci. Eng., 47, 209-217, 2005.

Verry, E. S. and Boelter, D. H.: Peatland hydrology, in: Wetland Functions and Values: the State of Our Understanding, Proceedings of the National Symposium on Wetlands, Lake Buena Vista, Florida, November 7-10, edited by: Greeson, P., American Water Research Association: Minneapolis, MN, 389-402, 1978.

Vogel, H. J.: Morphological determination of pore connectivity as a function of pore size using serial sections, Eur. J. Soil Sci., 48, 365-377, 1997.

Wadell, H.: Volume, Shape and Roundness of Quartz Particles, J. Geol., 43, 250-280, 1935.

Wang, J., Milne, D., Wegner, L., and Reeves, M.: Numerical evaluation of the effects of stress and excavation surface geometry on the zone of relaxation around open stope hanging walls, Int. J. Rock Mech. Min., 44, 2, 289-298, 2007.

White, F. M.: Viscous Fluid Flow, McGraw-Hill, New York, 1974. 